\title{
A prospective study of clinical and histopathological correlation of specimens of hysterectomies
}

\author{
Radha Rastogi ${ }^{1}$, Bharat Tailor $^{2 *}$, Vandana Patidar ${ }^{1}$
}

\author{
${ }^{1}$ Department of Obstetrics and Gynecology, RNT Medical College, Udaipur, Rajasthan, India \\ ${ }^{2}$ Junior Specialist, Sub Division Hospital, Bali, District Pali, Rajasthan, India
}

Received: 13 April 2021

Revised: 10 May 2021

Accepted: 11 May 2021

\author{
*Correspondence: \\ Dr. Bharat Tailor, \\ E-mail: sbapna.1@gmail.com
}

Copyright: $\odot$ the author(s), publisher and licensee Medip Academy. This is an open-access article distributed under the terms of the Creative Commons Attribution Non-Commercial License, which permits unrestricted non-commercial use, distribution, and reproduction in any medium, provided the original work is properly cited.

\begin{abstract}
Background: Uterus, a vital reproductive organ is subjected to many benign and malignant diseases. Although many medical and conservative surgical treatment options are available, hysterectomy still remains the most commonly performed major gynaecological operative procedure worldwide. Mostly it is the definitive treatment for many of its indications including abnormal uterine bleeding, like in case of fibroids, adenomyosis, utero-vaginal prolapse, endometriosis and pelvic inflammatory disease. Aims and objectives were to know the indications for hysterectomy and its various complications and to analyse correlation between the clinical indication with their histopathological findings. Methods: This hospital based study was conducted at RNT Medical College, Udaipur. A total of 200 case were included undergoing hysterectomy (any route) for gynecological disease. Surgical specimens were sent for histopathology and reports were analysed and compared with the indications of surgery.

Results: In this study preoperative indication of hysterectomy was leiomyoma (34.50\%) followed by utero vaginal prolapse (39.0\%) and adenomyosis (12.5\%) etc. Common finding of HPR report of specimens of uterus and adnexa are as follows: endometrium- proliferative phase $(44.50 \%)$, myometrium- leiomyoma $(33 \%)$, cervix- mild squamous hyperplasia (45\%), ovaries- physiological ovarian cyst $(25.50 \%)$. Pre-operative diagnosis of all cases of study were confirmed on histopathology. There was no major intraoperative complication in study group like bladder, rectum, ureter, visceral organ injuries etc. There was no life-threatening postoperative complication and all patients were discharged in good general condition.

Conclusions: In most cases diagnosis by HPR was similar with our preoperative diagnosis but in few cases HPR diagnosis may differ from preoperative diagnosis. Major complications were negligible, hence now-a-days hysterectomy is considered quite a safe procedure.
\end{abstract}

Keywords: HPR, Hysterectomy, Operative complications, Uterus

\section{INTRODUCTION}

Uterus, a vital reproductive organ is subjected to many benign and malignant diseases. Although many medical and conservative surgical treatment options are available, hysterectomy still remains the most commonly performed major gynaecological operative procedure worldwide. ${ }^{1}$ Mostly It is the definitive treatment for many of its indications including abnormal uterine bleeding, like in case of fibroids, adenomyosis, utero-vaginal prolapse, endometriosis and pelvic inflammatory disease, pelvic pain, gynaecological cancers and obstetric complications example atonic PPH, morbid adherent placenta, hydatidiform mole >35 year, septic abortion). Leiomyomas are the most common tumor in women during the reproductive years. ${ }^{2}$

Histopathological (gross and microscopic examination of tissue) examination of hysterectomy specimens 
therefore carries confirmation of diagnosis and if needed further management of patients. ${ }^{3}$

Hysterectomy derived from a Greek word, hystera means "uterus" and ektomia means "a cutting out of".

Hysterectomy is an operation which provides permanent symptom relief and patient satisfaction. It provides definitive cure to many diseases involving uterus as well as adnexa, e.g., fibroids, adenomyosis, endometriosis, pelvic inflammatory disease, pelvic organ prolapse and many malignancies.

\section{Abnormal uterine bleeding (AUB)}

Menstrual flow outside of normal volume, duration, regularity, or frequency is considered abnormal uterine bleeding (AUB). One third of patient visits to the gynecology OPD are for menstrual problems in reproductive years, and this increases to two third in the perimenopausal and postmenopausal years. ${ }^{4}$ The average duration of normal menstrual flow is generally 4.5 to 8 days, and the normal menstrual cycle typically lasts between 24 days and 38 days and an average blood loss of 20 to $80 \mathrm{ml}$. Descriptive terms that traditionally have been used to characterize abnormal menstrual bleeding patterns include menorrhagia, metrorrhagia, poly-menorrhea, and oligomenorrhea.

Menorrhagia is defined as cyclical bleeding at normal intervals, the bleeding is either excessive in amount (>80 $\mathrm{ml}$ ) or duration ( $>7$ days) or both. However, this definition is used for research purposes and, in practice, excessive blood loss should be based on the patient's perception. Metrorrhagia (intermenstrual bleeding) is defined as irregular, acyclic bleeding from uterus. Polymenorrhea is defined as bleeding that occurs more frequently than every 21 days, and oligomenorrhea is defined as bleeding that occurs less frequently than every 35 days. Hypomenorrhea is defined as when menstrual bleeding is unduly scanty and lasts for less than 2 days.

Dysfunctional uterine bleeding (DUB) is defined as a state of abnormal uterine bleeding without any clinically detectable organic, systemic and iatrogenic cause (pelvic pathology e.g. tumor, inflammation or pregnancy is excluded). It is used as a diagnosis rather than a symptom. DUB is often used as a diagnosis of exclusion. ${ }^{4}$

The term dysfunctional uterine bleeding is not part of the PALM-COEIN system, and discontinuation of its use is recommended. ${ }^{5}$

AUB (abnormal uterine bleeding) pattern have been traditionally expressed by terms like menorrhagia, metrorrhagia, polymenorrhea, and oligomenorrhea. In an effort to create a universally accepted system of nomenclature to describe uterine bleeding abnormalities in reproductive-aged women, a new classification system, known by the acronym PALM-COEIN was introduced in
2011 by the Inter- national Federation of Gynecology and Obstetrics (FIGO). ${ }^{5}$ The American College of Obstetricians and Gynecologists supports the adoption of the PALM-COEIN nomenclature system developed by FIGO to standardize the terminology used to describe AUB. The acronym PALM (structural causes) designated as polyp, adenomyosis, leiomyoma, malignancy- COEIN (nonstructural causes) designated as coagulopathy, ovulatory dysfunction, endometrial hyperplasia, iatrogenic, and not yet classified.

The PALM-COEIN system classifies uterine bleeding abnormalities by bleeding pattern as well as by etiology. The overarching term AUB is paired with descriptive terms to denote bleeding patterns associated with AUB, such as heavy menstrual bleeding (instead of menorrhagia) and intermenstrual bleeding (instead of metrorrhagia). Abnormal uterine bleeding is further classified by one (or more) letter qualifiers that indicate its etiology or etiologies (Figure 1) e.g.- AUB-A for adenomyosis of uterus.

\section{Aims and objectives}

To know the indications for hysterectomy and its various complications; to study demographic profile of patient undergoing hysterectomy; to analyse histopathological finding in histological specimen of uterus and adnexa; to analyse correlation between the clinical indication with their histopathological findings.

\section{METHODS}

This hospital based prospective observational study was conducted in the Department of Obstetrics and Gynecology, RNT Medical College, Udaipur, started from January 2019 and total of 200 case were included undergoing hysterectomy (any route) for gynecological disease, after taking clearance from the Institutional Ethical committee. Data was recorded including demographic characteristics and clinical features. Surgical specimens were sent for histopathology and reports were analysed and compared with the indications of surgery. Indication for the procedure was documented.

Hysterectomy for emergency conditions e.g. obstetrical haemorrhage, rupture uterus etc. were excluded.

Data was entered and analysed by using Microsoft Excel version 2010 and Statistical Package for Social Sciences ver.24 (SPSS.24). Appropriate test of significance was applied. $\mathrm{P}$ value $<0.05$ was considered statistically significant.

\section{RESULTS}

Abdominal hysterectomies done were $121(60.5 \%)$ and the number of vaginal hysterectomies done were 79 (39.5\%) (Figure 1). 


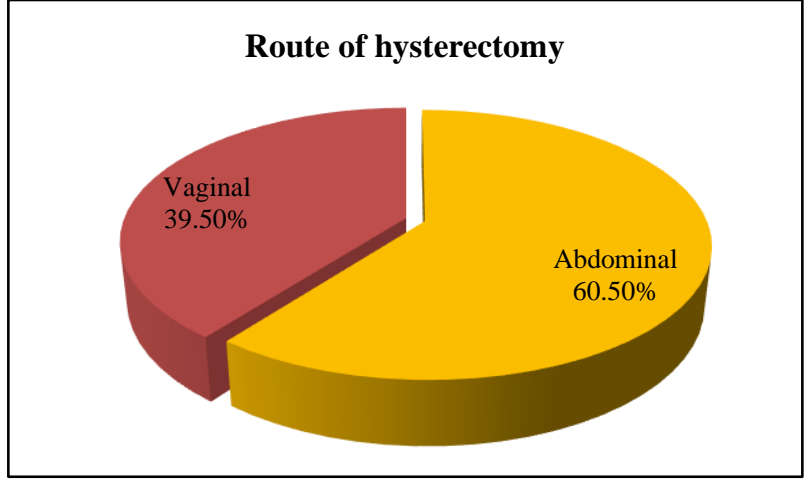

Figure 1: Distribution of 200 cases of hysterectomy according to route of hysterectomy.

Maximum number of cases of hysterectomy were done in the age group 41-50 (42.71\%). Maximum number of cases of abdominal hysterectomy were done in the age group 41$50(49.17 \%)$. Maximum number of vaginal hysterectomies were done in the age group 41-50 (42.71\%) years (Table $1)$.

Table 1: Age distribution of 200 cases of hysterectomy.

\begin{tabular}{|c|c|c|c|c|c|c|}
\hline \multirow{2}{*}{$\begin{array}{l}\text { Age group } \\
\text { (years) }\end{array}$} & \multicolumn{2}{|c|}{ Abdominal } & \multicolumn{2}{|c|}{ Vaginal } & \multicolumn{2}{|c|}{ Total } \\
\hline & No. & $\%$ & No. & $\%$ & No. & $\%$ \\
\hline$<20$ & 0 & 0 & 0 & 0 & 0 & 0 \\
\hline 21-30 & 1 & 0.83 & 0 & 0.00 & 1 & 0.50 \\
\hline 31-40 & 46 & 38.33 & 7 & 8.86 & 53 & 26.63 \\
\hline 41-50 & 59 & 49.17 & 26 & 32.91 & 85 & 42.71 \\
\hline $51-60$ & 11 & 9.17 & 25 & 31.65 & 36 & 18.09 \\
\hline$\geq 61$ & 4 & 2.50 & 21 & 26.58 & 25 & 12.06 \\
\hline Total & 121 & 100.00 & 79 & 100.00 & 200 & 100.00 \\
\hline
\end{tabular}

Table 2: Preoperative main diagnosis for hysterectomies.

\begin{tabular}{|lll|}
\hline $\begin{array}{l}\text { Preoperative main diagnosis } \\
\text { of hysterectomy }\end{array}$ & No. & Percentage \\
\hline Uterine prolapse & 78 & 39.00 \\
\hline Uterine leiomyoma & 69 & 34.50 \\
\hline Adenomyosis & 25 & 12.50 \\
\hline Pelvic inflammatory disease & 7 & 3.50 \\
\hline AUB N & 6 & 3.00 \\
\hline Endometrial polyp & 4 & 2.00 \\
\hline Chronic cervicitis & 4 & 2.00 \\
\hline Ovarian cyst & 2 & 1.00 \\
\hline Post menopausal bleeding & 1 & 0.50 \\
\hline Cervical polyp & 1 & 0.50 \\
\hline Endometrial cancer & 1 & 0.50 \\
\hline Cervical fibroid & 1 & 0.50 \\
\hline Uterine Inversion & 1 & 0.50 \\
\hline
\end{tabular}

In the present study principle indication for hysterectomy was utero vaginal prolapse $78(39.0 \%)$, followed by leiomyoma $69(34.50 \%)$ and adenomyosis $25(12.50 \%)$ (Table 2).

Table 3: Histopathological analysis of myometrium.

\begin{tabular}{|lll|}
\hline $\begin{array}{l}\text { Histopathological analysis of } \\
\text { myometrium }(\mathrm{n}=\mathbf{2 0 0})\end{array}$ & No. & Percentage \\
\hline Normal & 75 & 37.5 \\
\hline Fibroid & 69 & 34.5 \\
\hline Adenomyosis & 25 & 12.5 \\
\hline Myohyperplasia & 16 & 8 \\
\hline Atrophic & 15 & 7.5 \\
\hline
\end{tabular}

Histopathological reports of myometrium show $34.5 \%$ cases of leiomyoma, $12.5 \%$ cases of adenomyosis.

Table 4: Histopathological analysis of cervix.

\begin{tabular}{|ll|}
\hline $\begin{array}{l}\text { Histopathological analysis of } \\
\text { Cervix }\end{array}$ & $\begin{array}{l}\text { Number of } \\
\text { patients }\end{array}$ \\
\hline Squamous hyperplasia & $177(88.5 \%)$ \\
\hline Normal & $13(6.5 \%)$ \\
\hline Cervicitis & $9(4.5 \%)$ \\
\hline Cervical polyp & $1(0.5 \%)$ \\
\hline Dysplasia & $0(0 \%)$ \\
\hline
\end{tabular}

Squamous hyperplasia ( $88.5 \%$ ) was most common finding of cervix followed by normal in $6.5 \%$ cases, cervicitis in $4.5 \%$ and cervical polyp in $0.5 \%$ cases on histopathological examination (Table 4).

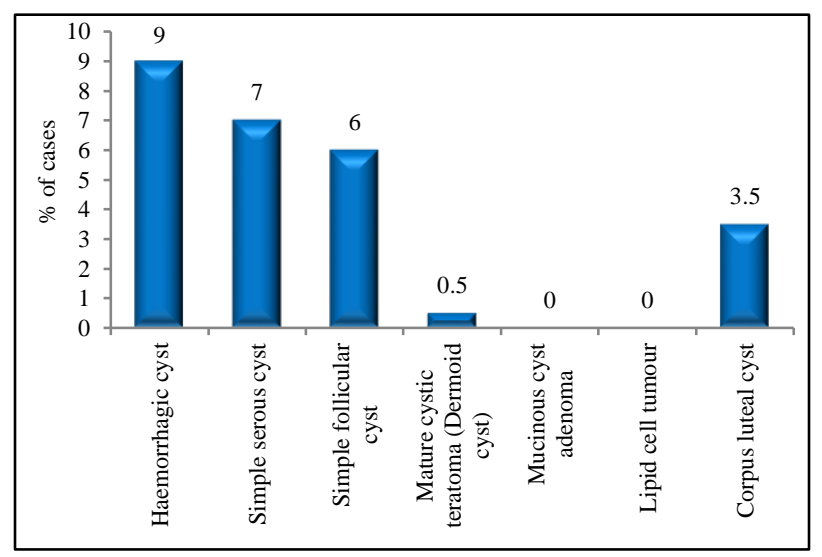

Figure 2: Histopathological analysis of ovaries (n=241).

On the basis of histopathological reports, physiological ovarian cysts was present in 51 cases, normal in 148 cases, and pathological finding was reported in 1 case only (Figure 2).

In case of fibroid all cases confirmed with HPR, out of total cases (25) of adenomyosis (25) all cases confirmed on HPR, all cases of endometrial polyp (4) and cervical polyp (1) confirmed on HPR (Table 5). 
Table 5: Comparison between preoperative diagnosis and histopathology findings.

\begin{tabular}{|lll|}
\hline $\begin{array}{l}\text { Preoperative } \\
\text { diagnosis of } \\
\text { hysterectomy }\end{array}$ & $\begin{array}{l}\text { Number } \\
\text { of cases }\end{array}$ & $\begin{array}{l}\text { Histopathology } \\
\text { findings correlate } \\
\text { with clinical } \\
\text { diagnosis }\end{array}$ \\
\hline Uterine leiomyoma & 69 & 71 \\
\hline Adenomyosis & 25 & 25 \\
\hline Endometrial polyp & 4 & 4 \\
\hline Chronic cervicitis & 4 & 5 \\
\hline Ovarian cyst & 2 & 52 \\
\hline Cervical polyp & 1 & 1 \\
\hline Endometrial cancer & 1 & 2 \\
\hline Cervical fibroid & 1 & 1 \\
\hline $\begin{array}{l}\text { Endometrial } \\
\text { hyperplasia }\end{array}$ & 0 & 2 \\
\hline Ovarian cancer & 0 & 0 \\
\hline Cervical cancer & 0 & 0 \\
\hline Chronic endometritis & 0 & 2 \\
\hline $\begin{array}{l}\text { Utero-vaginal } \\
\text { prolapse }\end{array}$ & 79 & - \\
\hline
\end{tabular}

Average postoperative stay was 5-7 days in almost $4 / 5$ patient. Average postoperative stay was 6.55 days, 6.48 days in vaginal and 6.6 days in abdominal (Table 6).

34 patients complained of symptoms related to gastrointestinal system (e.g. nausea, vomiting, diarrhea), mostly relieved by symptomatic management (antacid, i.v. fluid diet). One patient had urinary retention. One $(0.5 \%)$ had abdominal distension. Blood transfusion was done in $4 \%$ cases. Intraoperative blood transfusion done in 2 cases of abdominal hysterectomy and one case of vaginal hysterectomy. Postoperative blood transfusion done in 3 cases of abdominal hysterectomy and 7 cases of vaginal hysterectomy.

Table 6: Duration of hospital stay.

\begin{tabular}{|llll|}
\hline $\begin{array}{l}\text { Duration of } \\
\text { hospital stay }\end{array}$ & Abdominal & Vaginal & $\begin{array}{l}\text { Grand } \\
\text { total }\end{array}$ \\
\hline Mean & 6.60 & 6.48 & 6.55 \\
\hline Min. stay (days) & 3 & 5 & 3 \\
\hline Max. stay (days) & 21 & 14 & 21 \\
\hline 5-7 days & 173 & & 173 \\
\hline
\end{tabular}

Table 7: Complications of hysterectomy.

\begin{tabular}{|c|c|c|c|}
\hline Complications & Abdominal & Vaginal & Total \\
\hline Anaesthetic complication & 0 & 0 & 0 \\
\hline Intra operative injury to adjacent viscera & 0 & 0 & \multirow{4}{*}{0} \\
\hline Bladder & & & \\
\hline Ureter & & & \\
\hline Gut & & & \\
\hline Primary haemorrhage & 0 & 1 & 1 \\
\hline Secondary haemorrhage & 0 & 0 & 0 \\
\hline \multicolumn{4}{|l|}{ Blood and blood products transfusion } \\
\hline Intraoperative & 2 & 1 & 3 \\
\hline Postoperative & 3 & 2 & 5 \\
\hline Blood transfusion reaction & 0 & 0 & 0 \\
\hline Abdominal distension & 1 & 0 & 1 \\
\hline Paralytic ileus & 0 & 0 & 0 \\
\hline Unexplained fever & 2 & 0 & 2 \\
\hline Wound sepsis / dehiscence & 8 & 0 & 8 \\
\hline Gastro intestinal complication (nausea, vomiting and diarrhea) & 22 & 12 & 34 \\
\hline Urinary retention & 0 & 1 & 1 \\
\hline Bed sore & 0 & 0 & 0 \\
\hline Others & 1 & 0 & 1 \\
\hline
\end{tabular}

\section{DISCUSSION}

In the present study of 200 cases of hysterectomies, the number of abdominal hysterectomies done were 121 $(60.5 \%)$ and the number of vaginal hysterectomies done were $79(39.5 \%)$ (Figure 1), which were more than Sobande et al study in which abdominal was $52 \%$ and vaginal hysterectomy was $18.6 \%$, Ajmera Sachin et al study in which abdominal was $54.4 \%$ and vaginal was
38.9\% and less than Bukar et al study in which abdominal hysterectomy with either unilateral or bilateral salpingooophorectomy accounted for $73(79.3 \%)$ and vaginal hysterectomy contributed $19(20.7 \%)$ of cases. ${ }^{6-8}$

Abdominal hysterectomy is the preferred route of hysterectomy in our institution due to the practice and training, except in genital organ prolapse cases where vaginal hysterectomies were preferred, currently there is a 
changing attitude amongst gynaecologist in favour of vaginal hysterectomy (even in the absence for prolapse) for benign condition. Commonly popular as NDVH (nondescent vaginal hysterectomy).

In cases of ovarian cyst we did hysterectomy in cases where patient wants hysterectomy along with ovarian cystectomy due to completion of their family along with menstrual abnormality.

Maximum number of cases of hysterectomy were done in the age group $41-50(42.71 \%)$ (Table 1$)$, which coincides with the age range that reported by Rather et al and Perveen et al. ${ }^{9,10}$

Maximum number of cases of abdominal hysterectomy were done in the age group 41-50 (49.17\%) (Table 1), which coincides with the age incidence given by Miller et al 40.49 years, Mauzy et al 40-50 years, Johnson et al 4050 years, Benson and Sneedon 40-50 years, Sobande et al 46.8 years, Parveen et al years 41-50 years and above 35 years. ${ }^{6,10-14}$ Moreover, the age incidence of abdominal hysterectomy was found to be maximum in the age group 31-50 years (79.1\%), which is comparable to age given by Lazarus et al 30-50 years. ${ }^{15}$ This variation may be due to late menarche and late perimenopausal complication in western races.

Maximum number of vaginal hysterectomies were done in the age group $41-50(42.71 \%)$ years (Table 1$)$, which is comparable with Sobande et al of 41-50 years and less as compared to Sholapur (1982) 50 years, this is because the frequency of most common indication for abdominal hysterectomy i.e. leiomyoma, adenomyosis peak in the age group 31-50 year. ${ }^{6}$ Pelvic organ prolapse occurred in old ladies with peak frequency of 51-60 year (peri and post menopausal) but in our region due to early first delivery, delivery at home by dais, multiparity with early resumption of their homework, poor nutrition and anaemia and house wife working in squatting position it occurs earlier, equalizing the age of abdominal hysterectomy.

In the present study principle indication for hysterectomy was utero vaginal prolapse 78 (39.0\%) (Table 2), which was similar to Ajmera et al but more than Qamar-uy-nisa et al $19 \%$. $^{7,16}$

In the present study second common indication for hysterectomy was leiomyoma $69(34.50 \%)$, (Table 2) which was similar to Qamar-uy-nisa et al 33\%, Layla et al $34 \%$, Shergill et al 34\%, but less than Sajjad et al 39\%, Sarfaz et al $69 \%$, Bukar et al $39.1 \%$, but more than Intisar et al $21.5 \%$, Ramachandran et al $30.7 \% .^{16-22}$ Other common indications were adenomyosis, chronic cervicitis, PID etc.

Histopathological reports of myometrium shows $34.5 \%$ cases of leiomyoma, $12.5 \%$ cases of adenomyosis (Table 3 ) less than reported by Weir et al $13.14 \%$, equal to Wesley et al $11.1 \%$. $3 \%$ cases of fibroid uterus associated with adenomyosis which were equal to D'Esopo et al $2.8 \% .^{32,23}$

In our study squamous hyperplasia $(88.5 \%)$ was most common finding of cervix followed by normal in $6.5 \%$ cases, cervicitis in $4.5 \%$ and cervical polyp in $0.5 \%$ cases on histopathological examination (Table 4).

In our study $9 \%$ specimens shows cervicitis, less than Sarfraz et al $100 \%$ and approximated to Miller et al $7.7 \% .^{11,20}$

The most common finding of ovary in this study, on the basis of histopathological reports, were physiological ovarian cysts 51 cases, normal in 148 cases, and pathological finding were reported in 1 case only (Figure 2 ), while in Parveen study normal were $50 \%$, ovarian cyst $16.6 \%$, ovarian tumor $16.6 \%$, endometriosis $12.9 \% .^{24} \mathrm{We}$ have sent 241 ovaries for HPE. In which patient both ovaries were removed and we have counted both ovaries in one patient as per HPE.

Only few studies have done an audit by comparison of preoperative diagnosis with histopathological examination of specimens.

We have found that majority of pre-operative diagnosis of our cases were confirmed on histopathological examination. In cases of prolapse we are doing hysterectomy for symptoms related to uterovaginal prolapse, not because of pathology in uterus itself (Table $5)$.

In case of fibroid all cases confirmed with HPR, out of total cases (25) of adenomyosis (25) all cases confirmed on HPR, all cases of endometrial polyp (4) and cervical polyp (1) confirmed on HPR (Table 5), which was more than Lee et al found $80 \%$ concordance in $80 \%$ cases. $^{25}$ Miller et al studied 246 cases and $50 \%$ concordance rate was established. ${ }^{11}$ The clinicopathological correlation between preoperative diagnosis and histopathological examination was more than $90 \%$ especially in benign conditions in Vandana et al study. ${ }^{33}$

Cervical polyp have $100 \%$ diagnosis confirmed on histopathology and same was reported by Gupta et al. ${ }^{2}$

In present study relationship between clinical diagnosis and histopathology diagnosis were correlated more than study done by Dicker et al $52 \%{ }^{26}$ In our study adenomyosis confirmed in $92 \%$ cases which was more than study done by Lee $48 \% .^{25}$ In our study normal histopathology found in 93 cases $(46.50 \%)$ which was more than study done by Miller et al $31 \%$, Foster et al $16.9 \% .^{11,27}$

In only two case we have done hysterectomy for ovarian pathology, but on HPR in 52 ovaries having various lesions in which most common is physiological cyst (51 cases). 
In two cases we found abnormal endometrium findings e.g. simple endometrial hyperplasia without atypia in one case and complex endometrial hyperplasia without atypia in one case.

In the present study, average postoperative stay was 5-7 days in almost $4 / 5$ patient (Table 6 ).

In the present study, average postoperative stay was 6.55 days, 6.48 days in vaginal and 6.6 days in abdominal, (Table 6) similar to Perveen et al 5-7 days and longest stay of patient was 21 days in one case of abdominal hysterectomy due to wound dehiscence and 14 days in one case of vaginal hysterectomy due to problem of urinary retention. $^{24}$

Postoperative stay in maximum cases 194 (97\%) were within 10 days, which is comparable to that reported by Mengert et al 12.7 days, Perveen et al 5- $7^{\text {th }}$ day. ${ }^{34}$

In our study one patient had pre-existing cardiac disease precipitate, premature ventricular beats during surgery controlled by injection lignocaine. No intraoperative surgical complication occur in our study, which was equal to Benassi et al less than Boukerrou et al which had one bladder injury, one ileal injury and 4 cases of intraoperative haemorrhages, Martin et al $1.8 \%$ operative accidents (mainly bladder and ureter). ${ }^{29-31}$

In our study one patient $(0.5 \%)$ had postoperative bleeding per vaginum (primary haemorrhage) from posterior colpoperineorrhaphy repair haemostatic suture taken in evening on same day of surgery.

In present study $2(1 \%)$ patient suffer from unexplained fever, which was higher than Martin et al $0.5 \% .^{31}$

In present study $4(2 \%)$ patients had wound sepsis/dehiscence and $4(2 \%)$ patient had serous discharge (Table 7), which was less than Bukar et al with wound infection $(24.1 \%)$, Benassi et al $30.5 \%$, wound infection $1.40 \%$, wound dehiscence $1.87 \% .^{8,29}$

In present study one patient had urinary retention. In present study one patient $(0.5 \%)$ had abdominal distension. Blood transfusion done in $4 \%$ cases. Intraoperative blood transfusion done in 2 cases of abdominal hysterectomy and one case of vaginal hysterectomy. Postoperative blood transfusion done in 3 cases of abdominal hysterectomy and 7 cases of vaginal hysterectomy (Table 7). There was no mortality during the whole study period which was correspond to Vaidya et al. ${ }^{35}$ In our study 34 patients complained of symptoms related to gastrointestinal system (e.g. nausea, vomiting, diarrhea), mostly relieved by symptomatic management (antacid, i.v. fluid diet).

Reporting time of HPR procedures is required to be improved, so that if there is any growth, complication and/or diagnosis early intervention could be planned and performed.

\section{CONCLUSION}

We have correlated preoperative diagnosis by clinical method and/or various investigation with the HPR finding of specimens of uterus and appendages, and found that in most cases diagnosis by HPR is similar with preoperative diagnosis, but only in few cases HPR diagnosis differed from preoperative diagnosis. Hence we suggest to send all specimens for histopathological examination and if any variation is found than it should be noted and further management of patient should be done accordingly. We found that there were no major complications in hysterectomy patients. Hence now-a-day's hysterectomy is considered quite a safe procedure.

\section{Funding: No funding sources \\ Conflict of interest: None declared}

Ethical approval: The study was approved by the Institutional Ethics Committee

\section{REFERENCES}

1. Cunningham FG, Gant NF, Leveno KJ, Gilstrap LC, Hauth JC, Wenstrom KD. Cesarean Delivery and Peripartum hysterectomy. In: Cunningham FG, Gant NF, Leveno KJ, Gilstrap LC, Hauth JC, Wenstrom KD eds. Williams Obstetrics. 24th edn. USA: Mc Graw Hill Companies; 2014:587.

2. Gupta G, Kotasthane D. Hysterectomy: a clinicpathological correlation of 500 cases. Internet $\mathbf{J}$ Gynecol Obstet. 2009;14(1).

3. Graves EJ. National Centre for Health Statistics, National Hospital Discharge Survey, Annual Summary, 1990.

4. Spencer CP, Whitehead MI. Endometrial assessment re-visited. Br J Obstet Gynaecol. 1999;106:623-32.

5. Munro MG, Critchley HO, Broder MS, Fraser IS. FIGO classification system (PALM-COEIN) for causes of abnormal uterine bleeding in nongravid women of reproductive age. FIGO Working Group on Menstrual Disorders. Int $\mathbf{J}$ Gynaecol Obstet. 2011;113:3-13.

6. Sobande AA, Eskandar M, Archibong El, Damole. Elective hysterectomy: a clinicopathological review from Abha catchment area of Saudi Arabia. West Afr J Med. 2005;24(1):31-5.

7. Sachin AK, Mettler L, Jonat W. Operative spectrum of hysterectomy in a German university hospital. J Obstet Gynecol India. 2006;56(1):59-63.

8. Bukar M, Audu BM, Yahava UR. Hysterectomy for benign gynaecological conditions at Gombe, North eastern Nigeria. NMJ. 2010;51(1):35-8.

9. Rather RG, Gupta Y, Bardhwaj S. Pattern of lesion in Hysterectomy specimens. A prospective study. JK Sci. 2013;15:63-8. 
10. Perveen S, Tayyab S. A clinic pathological review of elective abdominal hysterectomy. J Surg Pak. 2008;13:26-9.

11. Miller NF. Hysterectomy: therapeutic necessity or surgical racket? Am J Obstet Gynecol. 1946;51: 804.

12. Mauzy CH, Lock FR, Donnelly JF. The management of fibromyomata uteri. Am J Obstet Gynecol. 1951;61(1):32-40.

13. Johnson CG, Moll Jr CF, Post L. An analysis of 6,891 hysterectomies for benign pelvic disease: With special reference to the safety of routine total abdominal hysterectomy. Am J Obstet Gynecol. 1956;71(3):51531 .

14. Benson RC, Sneeden VD. Adenomyosis: a reappraisal of symptomatology. Am J Obstet Gynecol. 1958;76(5):1044-61.

15. Lazarus J, Locke BZ, Thomas DS. Migration differentials in mental disease: State patterns in first admissions to mental hospitals for all disorders and for schizophrenia, New York, Ohio and California, as of 1950. Milbank Memor Fund Quart. 1963;41(1):2542.

16. Qamar-ur-Nisa, Habibullah, Shaikh TA, Hemlata, Memon F, Memon Z. Hysterectomies; an audit at Tertiary Care Hospital. Professional Med J. 2011;1:46-50.

17. Shergill SK, Shergill HK, Gupta M, Kaur S. Clinicopathological study of hysterectomies. J Indian Med Assoc. 2002;100(4):238-46.

18. Abdullah LS. Hysterectomy: A clinicopathologic correlation. Bahrain Med Bull. 2006;28(2):1-6.

19. Sajjad M, Iltaf S, Qayyum S. Pathological findings in hysterectomy specimens of patients presenting with menorrhagia in different age groups. Ann Pak Inst Med Sci. 2011;7(3):160-2.

20. Sarfraz R, Sarfraz MA, Kamal F, Afsar A. Pattern of benign morphological myometrial lesions in total abdominal hysterectomy specimens. Biomedica. 2010;26:140-3.

21. Pity IS, Jalal JA, Hassawi BA. Hysterectomy: a clinicopathologic study. Tilsit Med J 2011;17(2):7-16.

22. Ramachandran TS, Sinha R. Subramanium. Correlation between clinic pathological and ultrasonographic findings. J Clin Diagn Res. 2011;5(4):734-40.

23. D'Esopo DA. Hysterectomy when the uterus is grossly normal. Am J Obstet Gynecol. 1962;83(1):113-22.

24. Wesley RH. A clinicopathological review of elective abdominal hysterectomy. Am J Obst. Gyn. 1954;67:293.

25. Lee NC, Dicker RC, Rubin G, Oray HW. Confirmation of preoperative diagnosis for hysterectomy. Am J Obstet Gynaecol. 1984;150(3):283-7.

26. Dicker RC, Scally MJ, Greenspan JR, Layde PM, Ory HW, Maze JM, et al. Hysterectomy among women of reproductive age: trends in the United States, 19701978. JAMA. 1982;248(3):323-7.

27. Foster Jr HW. Removal of the normal uterus. South Med J. 1976;69(1):13-5.

28. Curtis WW, Suckow E, Huffman JW. Abdominal complete hysterectomy. Obstet Gynecol Survey. 1950;5(6):910.

29. Benassi L, Rossi T, Kaihura CT, Ricci L, Bedocchi L, Galanti B, et al. Abdominal or vaginal hysterectomy for enlarged uteri: a randomized clinical trial. Am J Obstet Gynecol. 2002;187(6):1561-5.

30. Boukerrou M, Lambaudie E, Narducci F Crepin G, Cosson M. Hysterectomy for benign lesions: what remains for the abdominal route? J Gynecol Obstet Biol Reprod. 2001;30(6):584-9

31. Martin X, Gjata A, Goltier F, Raudrant D Hysterectomy for a benign lesion: can the vaginal route be used in all cases? J Gynecol Obstet Biol Reprod. 1999;28(2):124-30.

32. Weir WC. Am J Obst. Gyn. 1948;52:218.

33. Vandana P, Khoiwal S. Evaluation of Acceptance, Safety and Expulsion of Postplancental Intrauterine Contraceptive Devices (PPIUCD). IJSR. 2020;9(2):10-11.

34. Mengert WF, Stolt R. Am J Obst Gyn. 1945;49:603.

35. Vaidya PK. Obst. Gyn. India. 1979;29:1222.

Cite this article as: Rastogi R, Tailor B, Patidar V. A prospective study of clinical and histopathological correlation of specimens of hysterectomies. Int J Reprod Contracept Obstet Gynecol 2021;10:2692-8. 